\title{
LIDERANÇA DE ENFERMEIROS NO \\ ENFRENTAMENTO À COVID-19 EM UM \\ HOSPITAL NA REGIÃO SUL DO BRASIL
}

\author{
LEADERSHIP OF NURSES IN COPING \\ WITH COVID-19 IN A HOSPITAL \\ IN THE SOUTHERN REGION OF BRAZIL
}

\section{LIDERAZGO DE ENFERMERAS EN LA LUCHA CONTRA EL COVID-19 EN UN HOSPITAL DE LA REGIÓN SUR DE BRASIL}

\author{
Ana Cristina Pretto Báo ${ }^{1}$ \\ Angela Enderle Candaten ${ }^{2}$ \\ Daiane da Rosa Monteiro ${ }^{3}$ \\ Simone Coelho Amestoy ${ }^{4}$
}

\begin{abstract}
Como citar este artigo: Báo ACP, Candaten AE, Monteiro DR, Amestoy SC. Liderança de enfermeiros no enfrentamento à COVID-19 em um hospital na Região Sul do Brasil. Rev baiana enferm. 2022;36:e37761.

Objetivo: relatar a experiência de liderança de enfermeiros no enfrentamento à COVID-19 em um hospital universitário na Região Sul do Brasil. Método: relato de experiência da atuação de enfermeiros-líderes no combate ao novo Coronavírus, no período de março a junho 2020, em um hospital de referência, no Sul do Brasil. Resultados: o relato teve por base as ações de prática avançada nos serviços de enfermagem, englobando pesquisa, educação, prática assistencial e gestão. Identificou-se algumas aproximações na atuação do enfermeiro-líder na Unidade de Terapia Intensiva COVID e na Unidade de Internação não referência, como: criação de protocolos e fluxos, treinamento das equipes de enfermagem, dimensionamento/realocação, adequações na assistência e diferentes sentimentos vivenciados. Conclusão: a liderança do enfermeiro frente à pandemia vem sendo permeada por inúmeros desafios, sendo necessário utilizar-se de suas habilidades e competências para proporcionar um ambiente de trabalho de qualidade, seguro e saudável.
\end{abstract}

Descritores: Enfermeiras e Enfermeiros. Liderança. Hospitais. Coronavirus. Prática Avançada de Enfermagem.

Objective: to report the experience of leading nurses in coping with COVID-19 in a university hospital in southern Brazil. Method: experience report of the performance of leading nurses in the fight against the new Coronavirus, from March to June 2020, in a reference hospital in southern Brazil. Results: the report was based on the actions of advanced practice in nursing services, encompassing research, education, care practice and management. Some approaches were identified in the performance of the nurse-leader in the COVID Intensive Care Unit and in the

Enfermeira. Mestra em Ciências. Universidade Federal do Rio Grande do Sul, Porto Alegre, Rio Grande do Sul, Brasil. abao@hcpa.edu.br. https://orcid.org/00000002-2747-7197.

2 Enfermeira. Doutora em Ciências da Saúde. Enfermeira do Serviço de Terapia Intensiva do Hospital de Clínicas de Porto Alegre. Porto Alegre, Rio Grande do Sul, Brasil. https://orcid.org/0000-0002-6717-8327.

3 Enfermeira. Mestra em Enfermagem. Enfermeira do Serviço de Internação Clínica do Hospital de Clínicas de Porto Alegre. Porto Alegre, Rio Grande do Sul, Brasil. https://orcid.org/0000-0002-4867-7219.

4 Enfermeira. Doutora em Enfermagem. Professora Associada da Universidade Federal de Pelotas, em exercício provisório na Universidade Federal do Vale do São Francisco. Petrolina, Pernambuco, Brasil. https://orcid.org/0000-000 I-83 I0-2I 57. 
Non-Reference Impatient Unit, such as: creation of protocols and flows, training of nursing teams, dimensioning/ relocation, adequacies in care and different feelings experienced. Conclusion: the nurse's leadership in the face of the pandemic has been permeated by numerous challenges, and it is necessary to use their skills and competences to provide a quality, safe and healthy work environment.

Descriptors: Nurses. Leadership. Hospitals. Coronavirus. Advanced Practice Nursing.

Objetivo: reportar la experiencia de enfermeras lideres en el enfrentamiento a COVID-19 en un hospital universitario del sur de Brasil. Método: informe de experiencia del desempeño de enfermeras líderes en la lucha contra el nuevo Coronavirus, de marzo a junio de 2020, en un hospital de referencia en el sur de Brasil. Resultados: el informe se basó en las acciones de la práctica avanzada en los servicios de enfermería, abarcando la investigación, la educación, la práctica del cuidado y la gestión. Se identificaron algunos enfoques en el desempeño de la enfermera-líder en la Unidad de Cuidados Intensivos COVID y en la Unidad de Hospitalización No Referencial, tales como: creación de protocolos y flujos, capacitación de equipos de enfermería, dimensionamiento/reubicación, adecuaciones en la atención y diferentes sentimientos experimentados. Conclusión: el liderazgo de la enfermera frente a la pandemia ha estado impregnado de numerosos desafios, y es necesario utilizar sus habilidades y competencias para proporcionar un ambiente de trabajo de calidad, seguro y saludable.

Descriptores: Enfermeras y Enfermeros. Liderazgo. Hospitales. Coronavirus. Enfermería de Práctica Avanzada.

\section{Introdução}

A pandemia do novo Coronavírus que se alastrou pelo mundo também chegou ao Brasil, causando inúmeras consequências e problemas em diversos setores da sociedade. O vírus $S e$ vere Acute Respiratory Syndrome Coronavirus 2 (SARS-CoV-2) ou Coronavírus da Síndrome Respiratória Aguda Grave 2 foi descoberto em dezembro de 2019, na cidade de Wuhan, na China, causador da COVID-19 ${ }^{(1-2)}$. A doença abrange sintomas leves, moderados e graves. Cerca de 80\% das pessoas acometidas pelo SARS-CoV-2 podem ser assintomáticas e 20\% irão apresentar dificuldades respiratórias, exigindo atendimento nos diferentes níveis de atenção à saúde, de acordo com a gravidade dos $\operatorname{casos}^{(2-3)}$.

Os serviços de saúde responsáveis pelo atendimento das pessoas acometidas pelo SARS-CoV-2 em muitas cidades do Brasil ficaram, em alguns momentos, à beira de uma crise. Esse contexto resultou em falta de leitos/vagas e sobrecarga de trabalho para as equipes de saúde atuantes em todos os níveis de atenção à saúde, inclusive no âmbito hospitalar, em virtude da ocupação dos leitos, afastamento de profissionais e pela necessidade de cuidados dos pacientes. Já se sabe que a transmissão ocorre por meio de contato direto, por gotículas respiratórias ou contato com secreções contaminadas ${ }^{(2)}$.
Referente às formas de proteção individual indicadas aos profissionais da saúde ao prestarem atendimento às pessoas acometidas pelo novo Coronavírus, recomenda-se o uso de equipamentos de proteção individual (EPIs) para precaução de contato e gotículas, como: óculos de proteção ou protetor facial, gorro, avental, luvas e máscaras cirúrgicas ou a N95. Esta última é indicada em todos os serviços de saúde ao prestar assistência ao paciente suspeito ou confirmado de COVID-19, principalmente em procedimentos geradores de aerossóis ${ }^{(2,4)}$.

A enfermagem constitui $50 \%$ da força de trabalho no campo da saúde, é responsável pelo cuidado direto aos pacientes $24 \mathrm{~h}$ por dia e vem prestando atendimento às vítimas da COVID-19. No contexto hospitalar concentra-se um número expressivo de profissionais (enfermeiros, técnicos e auxiliares de enfermagem), todos fundamentais no processo de cuidar. Destarte, a equipe de enfermagem tem vivenciado diversas situações preocupantes nesse cenário, exigindo do profissional enfermeiro, líder da equipe de enfermagem, atuação qualificada no gerenciamento do cuidado, assim como na gestão de recursos materiais e humanos.

O trabalho do enfermeiro é permeado por uma complexidade de ações que engloba, além 
dos cuidados ao paciente, desenvolvimento de atividades na esfera gerencial e de liderança, tomada de decisões assertivas, bem como gerenciamento de conflitos e de relacionamentos interpessoais. Além disso, compete a esse profissional direcionar condutas e planejar ações, com a finalidade de alcançar objetivos, cabendo-lhe a supervisão e a responsabilidade legal das atividades da equipe de enfermagem ${ }^{(5)}$. É mediante o exercício da liderança do enfermeiro que se obtém a sincronia do trabalho em equipe, um atendimento de qualidade e a diminuição dos erros de enfermagem, gerando melhores resultados para o paciente ${ }^{(6)}$. No entanto, a pandemia apresentou situações que requerem do enfermeiro decisões não programadas, para dar continuidade ao cuidado e ao gerenciamento dos serviços em meio à crise.

Frente às necessidades de organização e reorganização de práticas assistenciais do serviço de enfermagem requeridas pela pandemia, pode-se dizer que exercer a liderança tem sido tarefa árdua para os enfermeiros que estão na linha de frente contra o novo Coronavírus. Diante disso, realizou-se um relato de experiência, instigado pela seguinte questão norteadora: De que maneira o enfermeiro vem exercendo o papel da liderança no enfrentamento da pandemia de COVID-19? Frente ao exposto, tem-se como objetivo relatar a experiência de liderança de enfermeiros no enfrentamento à COVID-19, em um hospital universitário na Região Sul do Brasil.

\section{Método}

Trata-se de relato de experiência acerca da liderança de enfermeiros no enfrentamento à COVID-19, em um hospital universitário localizado no Sul do Brasil. A instituição hospitalar conta com um total de 831 leitos, divididos em diversas áreas. Destes, 50 leitos em unidade de internação (UI) e 105 leitos em unidade de terapia intensiva (UTI) são destinados para atendimento à COVID-19. Conforme a demanda, de acordo com o plano de contingência, um número maior de leitos poderá estar disponível para o atendimento.
Diante dos casos de COVID-19 no Brasil, desde o mês de março de 2020, os dirigentes do hospital buscaram auxílio dos setores e dos profissionais da instituição, entre eles os enfermeiros, para planejar a estrutura, o dimensionamento de pessoal, os treinamentos dos profissionais e o preparo das equipes de enfermagem para o recebimento e tratamento dos pacientes, visando qualificação e excelência no atendimento aos acometidos pela nova doença.

Para o presente relato foram consideradas as reflexões e experiências vivenciadas por enfermeiros-líderes, atuantes em uma UTI e UI, durante o cotidiano profissional na pandemia, no período de março a junho de 2020. Em seguida, descreveu-se o dia a dia dos enfermeiros, líderes de suas equipes, nos dois diferentes cenários, contrastando com a literatura encontrada acerca da liderança.

\section{Relatos da experiência}

Após a configuração de um Grupo (multidisciplinar) de Enfrentamento ao novo Coronavírus, a instituição hospitalar construiu planos de contingência, fluxos e protocolos, diretrizes de paramentação/desparamentação, uso de EPIs, restrições de visitas, estratégias de atendimento à saúde mental dos trabalhadores e elaboração de projetos de pesquisa acerca do tema. Tais atividades foram elaboradas estrategicamente, para suprir a demanda de atendimentos e garantir a segurança dos profissionais e pacientes acometidos pela COVID-19.

No que se refere à estrutura física, foram destinadas áreas exclusivas para o atendimento de pacientes suspeitos/confirmados de Coronavírus. Na chegada do paciente suspeito de COVID-19 na emergência, no caso de apresentar sintomas gripais, este era destinado a uma área separada. Posteriormente, caso não tivesse sido liberado para isolamento domiciliar, seria encaminhado para a UI que atendia apenas casos confirmados ou, em situações mais graves, para a UTI, com a finalidade de receber uma assistência avançada. Não obstante dispor de unidades exclusivas para o atendimento de pacientes com o 
novo Coronavírus, a instituição inteira preparou-se para a pandemia, visto que, os reflexos da doença iriam atingir todas as áreas e setores.

Diante do exposto, emergiu a necessidade de relatar como vem sendo exercida a liderança dos enfermeiros-líderes de uma UTI referência para pacientes com COVID-19 e de uma UI não referência; duas realidades diferentes, mas com muitas aproximações. Assim, este relato está baseado nas ações de prática avançada nos serviços de enfermagem.

A enfermagem com prática avançada (EPA) é atualmente considerada uma inovação, visto que contribui com a melhoria da qualidade da assistência, assim como há evidências de altos índices de satisfação dos pacientes no cuidado e na diminuição dos custos da saúde ${ }^{(7)}$. Os pontos abordados nos relatos deste estudo serão as dimensões: pesquisa, educação, prática assistencial e gestão ${ }^{(8)}$.

\section{Liderança do enfermeiro em uma UTI}

Em meados do mês de fevereiro de 2020, o Ministério da Saúde (MS) dirigiu ao hospital em questão o desafio da ampliação dos leitos de terapia intensiva para o atendimento aos pacientes acometidos pela COVID-19. O Centro de Terapia Intensiva (CTI), composto por 47 leitos, deveria ser ampliado para um total de 152 leitos até o final do mês de maio de 2020. Para tanto, organizou-se frentes de trabalho junto à gestão do Serviço de Terapia Intensiva (SETI), para iniciar a organização, o planejamento e a abertura dos novos leitos.

No contexto desta pesquisa, buscou-se referências para a prática baseada em evidência. Grupos de trabalho foram construídos de forma multidisciplinar e foi revisada a literatura nacional e internacional, para dar início à elaboração de fluxos, protocolos e readaptações às rotinas de prática clínica. Os enfermeiros integraram cada grupo de trabalho conforme sua expertise. Nesse momento, percebeu-se a necessidade de ouvir toda a equipe, para que as demandas coletivas e adaptadas à realidade de cada profissional pudessem ser atendidas.
No que se refere à educação, com base na revisão de literatura anterior, os grupos iniciaram um conjunto de treinamentos in loco acerca das práticas assistenciais adotadas no atendimento aos pacientes suspeitos/confirmados com a doença. A primeira temática, e talvez a mais emergente, foi a paramentação/desparamentação dos profissionais. Garantir a segurança dos profissionais foi uma constante preocupação de todos os grupos de trabalho. Os enfermeiros sinalizaram a necessidade de treinamento imediato, visto que a internação do primeiro caso suspeito de Coronavírus já era anunciada pela Central de Leitos do Estado do Rio Grande do Sul.

Durante o processo de treinamento das equipes, o primeiro paciente suspeito chegou à UTI, o que gerou um misto de sentimentos nas equipes assistenciais. Imediatamente, os enfermeiros da unidade que atenderam o primeiro paciente estruturaram fluxos de entrada e saída dos profissionais, adaptaram a estrutura física, para garantir a segurança dos processos e reajustaram as escalas de trabalho, para dimensionar os profissionais mais experientes e que já tivessem recebido treinamento para atendimento aos pacientes com COVID-19.

Em meio à expressiva ampliação de novos leitos de terapia intensiva, foi necessária a contratação imediata de novos profissionais. Após esse momento, desencadeou-se um movimento intenso para capacitação e treinamento das equipes. Foram elaborados treinamentos na modalidade presencial, em serviço e na modalidade de Educação a Distância (EaD). Ainda, buscando familiarização e agilidade, proporcionou-se situações práticas e simulações realísticas de vários cenários de atendimento.

Destaca-se que o papel do enfermeiro-líder na educação permanente torna-se impreterível em meio à pandemia. Conforme já foi evidenciado em uma pesquisa, considerar as demandas da equipe de enfermagem e planejar ações educativas voltadas para a prática diária, pode ser uma maneira de contribuir com a obtenção de melhores resultados assistenciais ${ }^{(9)}$.

Em relação à prática assistencial, diante do novo cenário, mostrou-se necessária a adaptação 
das rotinas assistenciais. Com o escopo de garantir uma assistência de enfermagem segura e de qualidade, foram elaborados protocolos e fluxos de atendimento, de acordo com as exigências propostas pelo MS e por órgãos regulamentadores. Nesse sentido, foram modificados processos de trabalho como: dispensação de medicamentos, fluxos de entrada e saída de resíduos, transporte/ transferência de pacientes, fluxo de visitas, serviços de apoio, fluxo dos materiais provenientes do Centro de Materiais e Esterilização, fluxo de óbito, documentos do paciente e rotinas administrativas, além de modificações e recomendações de boas práticas na assistência ventilatória (uso de ventilação mecânica, ventilação mecânica não invasiva, terapia inalatória, intubação orotraqueal e posição prona). A equipe de trabalho também recomendou modificações de rotinas de cuidados de enfermagem, a fim de evitar exposições desnecessárias. Todos os fluxos foram revisados e atualizados diariamente pelo enfermeiro-líder, visto que a ocupação e as necessidades assistenciais da unidade são dinâmicas e estão em constante adaptação.

O gerenciamento de boas práticas é primordial para a assistência à saúde livre de danos. Além disso, como já visto em estudo ${ }^{(10)}$, promove o planejamento do cuidado individualizado, de acordo com as necessidades de cada paciente. Nesse ínterim, o olhar do enfermeiro-líder para as boas práticas em saúde, mediante a prática baseada em evidências, suscita assistência segura e de qualidade.

Sob a ótica da gestão, organizou-se a análise da estrutura, de pessoas e processos.

Gestão de estrutura - os novos leitos de UTI para pacientes acometidos pelo Coronavírus foram alocados no bloco anexo ao prédio principal. Uma estrutura física destinada à Emergência foi adaptada para UTI e foram abertos clusters de oito e dez leitos a cada início de semana. Ao final, 105 novos leitos de UTI foram instalados e os enfermeiros foram responsáveis pela organização das novas unidades, gerenciamento de equipamentos, materiais e medicamentos, em conjunto com o setor administrativo e a farmácia. A principal dificuldade diante do cenário foi a corrida contra o tempo. Em um curto período, foi necessária a reorganização da infraestrutura física da instituição, em virtude dos casos do momento e também para atender a demanda crescente de pacientes com COVID-19. Entre as estratégias para a rápida reorganização, a instituição contou com a expertise dos profissionais, o planejamento estratégico das ações e a governança das melhores práticas.

Gestão de pessoas - após a contratação emergencial de inúmeros novos profissionais, os enfermeiros foram desafiados a dimensionar a equipe de enfermagem de maneira diferente do habitual: distribuindo enfermeiros e técnicos de enfermagem experientes em diferentes unidades, para que auxiliassem na preparação e no treinamento dos profissionais recém-chegados e inexperientes no cuidado ao paciente crítico com COVID-19. Buscando o melhor aproveitamento de habilidades dos profissionais, técnicos experientes das UIs foram realocados na UTI, para auxiliar no atendimento aos pacientes graves. Esse movimento (necessário) gerou impacto emocional nas equipes e esses sentimentos foram acolhidos pelos enfermeiros-líderes em conjunto com o serviço de psicologia da instituição, que ofertou momentos de escuta semanal. Um estudo nacional, realizado com profissionais de enfermagem que atuam diretamente no combate ao novo Coronavírus, identificou que a pandemia tem gerado diversos sentimentos nesses trabalhadores, tais como ansiedade, medo, ambivalência, depressão e exaustão, relacionados principalmente à falta de EPIs, ao grande número de óbitos e infectados, ao afastamento dos familiares e ao excesso de trabalho ${ }^{(11)}$.

Uma das queixas da equipe assistencial foi a falta de identidade pessoal oculta pela paramentação. Com vistas a mitigar essa lacuna, a fim de tornar os "rostos visíveis" aos pacientes e colegas, foram confeccionados crachás especiais com a foto ampliada dos rostos de cada membro da equipe. Tal atitude gerou satisfação aos profissionais da enfermagem pelo trabalho e valorização da identidade de cada um.

Gestão de processos - no período de adaptações diárias, fez-se necessário o acompanhamento de todos os processos administrativos e 
assistenciais. O enfermeiro acompanhava diariamente a evolução da ampliação do serviço, as necessidades de educação permanente, os indicadores e as metas assistenciais, os processos de controle de qualidade e segurança, a incidência de contaminações entre profissionais, a revisão dos protocolos assistenciais e de gestão, o acompanhamento e rastreamento de esgotamento psicológico das equipes de enfermagem, bundles diários para mapeamento de riscos ocupacionais e assistenciais. A divulgação de novas orientações frente à pandemia e o combate às fake news foi algo que precisou ser levado em consideração pelo grupo de trabalho. Diante disso, informações atualizadas e fidedignas eram disponibilizadas diariamente às 7 horas da manhã, no painel de controle da intranet da instituição. Tal iniciativa exigiu esforços integrados de profissionais de tecnologia da informação, além da parceria com as áreas assistenciais na coleta de informações.

\section{Liderança do enfermeiro em uma UI}

Ao passo que as UTIs recebiam os primeiros pacientes com COVID-19, as UIs clínicas destinadas para o atendimento de pacientes clínicos do hospital também passavam por reestruturações. Inicialmente, duas UIs foram destinadas ao atendimento exclusivo a esses pacientes. A UI relatada neste estudo, mesmo não sendo uma unidade de referência para pacientes COVID-19 positivo, engajou-se na atualização das equipes de enfermagem acerca dos fluxos assistenciais, pois existia a preocupação de que, num futuro próximo, a demanda poderia aumentar e outras unidades poderiam vir a atender os mesmos pacientes.

No que tange à pesquisa, inicialmente, os enfermeiros-líderes também precisaram conhecer os protocolos e fluxos institucionais (construídos por meio da literatura disponível) e divulgá-los para as equipes de enfermagem. Os protocolos permaneciam em constante atualização, conforme diretrizes nacionais e internacionais $e$ eram repassados às equipes pelas lideranças. As equipes de enfermagem mostraram-se abertas e dispostas a auxiliar, embora estivessem muito preocupadas e apreensivas com a possibilidade de realizar assistência aos pacientes com suspeita ou diagnóstico de COVID-19.

Em relação à educação, os integrantes de uma Comissão foram destinados a treinar as equipes de enfermagem para a paramentação/desparamentação no atendimento de pacientes com suspeita ou confirmação da doença. Devido ao improviso da estrutura física, dúvidas emergiram da equipe que passaria a atuar num ambiente adaptado e desconhecido. Nesse momento, as equipes puderam sanar suas dúvidas acerca da utilização dos EPIs, assim como tiveram acesso a todos os EPIs que deveriam ser utilizados. Também foram disponibilizados vídeos com atualizações acerca dos protocolos de atendimento, via intranet da instituição, deixando as equipes em consonância com os setores que já estavam atendendo pacientes com o novo Coronavírus. Para compartilhamento das informações e atualização sobre o assunto em questão, na UI do estudo, as enfermeiras-líderes disponibilizavam um painel com os fluxogramas de atendimento aos pacientes com suspeita de COVID-19 e também os Protocolos Operacionais Padrão (POP) para o atendimento.

A proteção dos profissionais de saúde é essencial para o atendimento de pacientes infectados, a fim de garantir que estes não atuem como transmissores do vírus. Ainda, os serviços de saúde possuem o dever de fornecer a capacitação para os profissionais de saúde na prevenção da transmissão de agentes infecciosos, assim como para o uso correto e seguro dos EPIs ${ }^{(4)}$.

Quanto às atualizações na prática assistencial, cabe informar que, por não se tratar de uma unidade de referência, não houve alterações na prática assistencial propriamente dita. Entretanto, os pacientes proveniente de Unidades COVID, após diagnóstico negativo, eram transferidos para UIs não referência. As principais mudanças da assistência foram aquelas relacionadas à alocação de profissionais. Funcionários provenientes do processo seletivo emergencial, que necessitavam de supervisão direta pela inexperiência no cuidado aos pacientes mais complexos, foram direcionados à UI para treinamento. Dessa forma, os técnicos de enfermagem adaptaram-se à realização de tarefas assistenciais, acompanhados de 
um colega recém-admitido, demandando maior atenção do enfermeiro na supervisão das atividades e na motivação das equipes.

Destaca-se as medidas adotadas na UI, com base na gestão de estrutura, pessoas e processos.

Com relação à gestão de estrutura, não foi preciso realizar alterações estruturais, visto que a unidade não foi destinada ao atendimento direto aos pacientes com COVID-19. No entanto, foram necessários o conhecimento e a divulgação das mudanças estruturais que vinham ocorrendo na instituição, visando transparência das informações para os funcionários. Com isso, os enfermeiros-líderes confeccionaram um mural explicativo na unidade acerca das mudanças decorrentes da pandemia e também as dúvidas sobre a transmissão e a prevenção da doença.

Com relação à gestão de pessoas, devido à demanda institucional, foi necessária a realocação de profissionais experientes das UIs para a UTI, a fim de proporcionar maior suporte técnico-científico para as áreas críticas, cujos pacientes exigiam maior complexidade de cuidados. Dessa forma, a unidade passou a receber profissionais inexperientes para o desenvolvimento das práticas assistenciais. O principal desafio desses profissionais foi o esgotamento dos colegas de referência da equipe devido à alta demanda de supervisão e aos ensinamentos no ambiente de trabalho, atrelados à rotina demandante de assistência direta ao paciente.

A sensibilização e o acolhimento dos sentimentos desses profissionais foram realizados pelos enfermeiros em cada turno de trabalho, com reforços diários e escuta qualificada por parte do serviço de psicologia hospitalar. Buscou-se também uma forma de homenagear a dedicação dos profissionais de enfermagem da referida unidade. Um grupo de publicitários, com o auxílio de alguns enfermeiros, realizou uma ação chamada Rede de Afeto. Nela, 59 pessoas foram convidadas a enviar um recado para um profissional do grupo, uma mensagem inspiradora para esse momento tão delicado.

Outro desafio para os enfermeiros-líderes dessa UI foram os atestados dos profissionais que apresentavam sintomas da doença, necessitando de afastamento e refletindo no redimensionamento das equipes. Na tentativa de diminuir a sobrecarga dos funcionários, os enfermeiros reuniram-se, e elencaram rotinas prioritárias para os pacientes, de maneira a não prejudicar a segurança e a qualidade do cuidado. Também houve uma parceria entre o Serviço de Medicina Ocupacional (SMO) e os enfermeiros, de maneira que estes eram avisados logo que o funcionário iria fazer o teste para COVID-19 ou testava positivo, assim como a programação dos dias de afastamento. O gerenciamento de escalas de trabalho é de suma importância, para que os profissionais das equipes de enfermagem não fiquem sobrecarregados ${ }^{(12)}$, tornando-se um elemento impactante para as lideranças.

Com relação à gestão de processos, foi necessária a adaptação da unidade ao novo cenário exposto, aderindo aos protocolos institucionais. Com isso, também se construiu um protocolo de transferência/transporte de pacientes para unidades referência no atendimento dos casos, visto que poderia acontecer pacientes da UI clínica, já internados por outro diagnóstico, positivar o exame para Coronavírus durante a internação e necessitar de transferência.

Também foi necessário suspender as visitas, e os acompanhantes só eram permitidos mediante avaliação do enfermeiro, de forma isolada, a fim de evitar aglomerações e possíveis focos de transmissão. Esta situação exigiu sensibilização e orientação aos familiares.

Líderes na enfermagem são imprescindíveis para salvaguardar o desenvolvimento estratégico e contínuo do ensino, da pesquisa e da prática de enfermagem. A pandemia causada pelo novo Coronavírus colocou em discussão o papel da liderança, uma necessidade nunca tão importante como agora ${ }^{(13)}$. Dessa forma, os enfermeiros-líderes foram engajados em promover cuidados de qualidade e enfrentar as dificuldades emergentes, com base no conhecimento científico e em sua vivência prática.

Como limitação do estudo, destaca-se que consiste em um relato de experiência em uma única instituição de saúde. Sendo assim, sugere-se que novos relatos acerca da liderança de 
enfermeiros no enfrentamento da COVID-19 possam ser compartilhados, tendo em vista os diferentes cenários de atuação do profissional.

\section{Conclusão}

O relato propiciou descrever a experiência acerca da liderança do enfermeiro no enfrentamento à COVID-19, em um hospital universitário no Sul do Brasil. No que tange à liderança do profissional enfermeiro, pode-se dizer que, nesse cenário, foi preciso utilizar-se de suas habilidades e competências, para proporcionar um ambiente de trabalho de qualidade, seguro e saudável para toda a equipe de enfermagem. Diante da habilidade de gestão e de liderança nas ações de melhoria no enfrentamento à COVID-19, o enfermeiro mostrou-se um importante elo entre a gestão institucional e a gestão do cuidado diário entre a equipe multidisciplinar. A comunicação assertiva, o clima de apoio, a educação permanente, a coordenação e supervisão do cuidado mostraram-se necessários para que o clima de tensão, incertezas e medo fossem amenizados.

Ao findar tal relato de experiência, é possível identificar algumas aproximações entre a UTI-COVID e a UI não referência, como: utilização de protocolos e fluxos baseados em evidências científicas, treinamento das equipes de enfermagem, dimensionamento/realocação de pessoal, adequações na prática assistencial e diferentes sentimentos vivenciados pelos profissionais. No entanto, para a criação da UTI-COVID foi necessária uma estrutura física nova, além de muitas ações voltadas para a gestão de pessoal, devido ao grande número de profissionais recém-admitidos. Cabe sinalizar que a liderança do enfermeiro esteve presente em ambos os cenários, buscando amenizar e minimizar os efeitos da pandemia, com vistas à manutenção da saúde do trabalhador e ao gerenciamento do cuidado ao paciente.

Os enfermeiros-líderes que trabalham na UTI e UI foram apoiados pela instituição e buscaram atuar conforme os pilares da pesquisa, educação, assistência e gestão, para criar e recriar condições favoráveis para o enfrentamento da pandemia, alavancando esforços mútuos, com o intuito de qualificar a assistência, agilizar os processos, atuar de modo técnico-científico, humanizando o cuidado e impulsionando um olhar diferenciado para as necessidades da equipe de enfermagem, principalmente no que tange aos aspectos emocionais.

A liderança do enfermeiro vem sendo tarefa árdua para os profissionais que estão na linha de frente da pandemia, visto que o cenário é de constantes mudanças e ainda necessita de um olhar de gestão inovador, diferenciado e desafiador.

\section{Colaborações:}

1 - concepção, projeto, análise e interpretação dos dados: Ana Cristina Pretto Báo, Angela Enderle Candaten, Daiane da Rosa Monteiro e Simone Coelho Amestoy;

2 - redação do artigo e revisão crítica relevante do conteúdo intelectual: Ana Cristina Pretto Báo, Angela Enderle Candaten e Simone Coelho Amestoy;

3 - aprovação final da versão a ser publicada: Ana Cristina Pretto Báo e Angela Enderle Candaten.

\section{Referências}

1. Zhang Y, Koopmans M, Yuen KY, Andersen K, Perlman S, Hogue B. The Novel Coronavirus Outbreak: What We Know and What We Don't. Cell. 2020;180(6):1034-6. DOI: 10.1016/j. cell.2020.02.027

2. Brasil. Ministério da Saúde. Secretaria de Atenção Especializada à Saúde. Departamento de Atenção Hospitalar, Domiciliar e de Urgência. Protocolo de Manejo Clínico da Covid-19 na Atenção Especializada [Internet]. Brasília (DF); 2020 [cited 2020 May 27]. Available from: https:// bvsms.saude.gov.br/bvs/publicacoes/manejo_ clinico_covid-19_atencao_especializada.pdf

3. World Health Organization. Naming the coronavirus disease (COVID-19) and the virus that causes it [Internet]. Geneva (CH); 2020 [cited 2020 May 27]; Available from: https://www.who.int/emergencies/diseases/ novel-coronavirus-2019/technical-guidance/ 
naming-the-coronavirus-disease-(covid-2019)and-the-virus-that-causes-it

4. Agência Nacional de Vigilância Sanitária. Nota Técnica GVIMS/GGTES/ANVISA 04/2020. Orientações para serviços de saúde: medidas de prevenção e controle que devem ser adotadas durante a assistência aos casos suspeitos ou confirmados de infecção pelo novo Coronavírus (SARS-CoV-2) [Internet]. Brasília (DF); 2020 [cited 2020 Jun 5]. Available from: http:// portal.anvisa.gov.br/documents/33852/271858/ Nota+T\%C3\%A9cnica+n+04-2020+GVIMS-GGTESANVISA/ab598660-3de4-4f14-8e6f-b9341c196b28

5. Reis CD, Amestoy SC, Silva GTR, Santos SD, Varanda PAG, Santos IAR, et al. Situações estressoras e estratégias de enfrentamento adotadas por enfermeiras líderes. Acta Paul Enferm. 2020;33:eAPE20190099. DOI: https://doi. org/10.37689/acta-ape/2020ao0099

6. Freire GV, Araújo ETH, Araújo EB, Alves LS, Freire ACM, Souza GF. Liderança do enfermeiro nos serviços de urgência e emergência: revisão integrativa. Braz J Hea Rev. 2019;2(3):2029-41. DOI: $10.5216 /$ ree.v16i1.19615

7. Bryant-Lukosius D, Martin-Misener R. Advanced Practice Nursing: An Essential Component of Country Level Human Resources for Health [Internet]. Geneve (CH): ICN Policy Brief; 2016 [cited 2017 Jun 3]. Available from: https://www. who.int/workforcealliance/knowledge/resources/ ICN_PolicyBrief6AdvancedPracticeNursing.pdf

8. Miranda Neto MV, Rewa T, Leonello VM, Oliveira MAC. Prática avançada em enfermagem: uma possibilidade para a Atenção Primária em
Saúde? Rev Bras Enferm. 2018;71(Suppl1):716-21. DOI: https://doi.org/10.1590/0034-7167-2017-0672

9. Sade PMC, Peres AM, Brusamarelo T, Mercês NNA, Wolff LDG, Lowen IMV. Demandas de educação permanente de enfermagem em hospital de ensino. Cogitare Enferm. 2019; 24:e57130. DOI: http://dx.doi.org/10.5380/ce. v24i0.57130

10. Báo ACP, Amestoy SC, Moura GMSS, Trindade LL. Quality indicators: tools for the management of best practices in Health. Rev Bras Enferm. 2019;72(2):360-6. DOI: http://dx.doi.org/10.1590/ 0034-7167-2018-0479

11. Humerez DC, Ohl RIB, Silva MCN. Mental health of Brazilian nursing professionals in the context of the COVID-19 pandemic: action of the Nursing Federal Council. Cogitare enferm [Internet]. 2020 [cited 2020 Jun 14];25:e74115. Available from: https://revistas.ufpr.br/cogitare/ article/view/74115/pdf_en

12. Fernandes CB, Cunha AM, Hemkemaier ECRC, Carmo KS, Moraes TVP, Santos TP, et al. Desafios e recomendações para o cuidado intensivo de adultos críticos com doença de coronavírus 2019 (COVID-19). Health Resid J. 2020;1(1):Edição Inaugural. DOI: https://doi.org/10.51723/hrj.v1i1.20

13. Daly J, Jackson D, Anders R, Davidson PM. Who speaks for nursing? COVID-19 highlighting gaps in leadership. J Clin Nurs. 2020;29(15-16): 2751-2. DOI: $10.1111 /$ jocn. 15305

Recebido: 12 de julho de 2020

Aprovado: 27 de maio de 2021

Publicado: 16 de fevereiro de 2022

A Revista Baiana de Enfermagem utiliza a Licença Creative Commons - Atribuição-NãoComercial 4.0 Internacional. https://creativecommons.org/licenses/by-nc/4.0/

Este artigo é de acesso aberto distribuído sob os termos da Licença Creative Commons (CC BY-NC). Esta licença permite que outros remixem, adaptem e criem a partir do seu trabalho para fins não comerciais. Embora os novos trabalhos tenham de lhe atribuir o devido crédito e não possam ser usados para fins comerciais, os usuários não têm de licenciar esses trabalhos derivados sob os mesmos termos. 